\title{
MODELING OF THE SATURATION REACTOR IN THE PRODUCTION OF PUMPKIN CANDIED FRUITS
}

\author{
${ }^{1}$ Iryna Huzova, ${ }^{2}$ Volodymyr Atamanyuk
}

Department of Chemical Engineering Lviv Polytechnic National University Bandera street, 12, Lviv, Ukraine, $79013^{1}$ Email: iryna.o.huzova@1pnu.ua. ${ }^{2} \mathrm{E}-\mathrm{mail}$ : atamanyuk@ukr.net

With the help of the universal simulation program ChemCad, an isothermal saturation reactor for sugar pumpkin particles was modeled, which operates under the constant concentration of sucrose in syrup and simultaneously increases the concentration of sucrose in candied fruits. Concentration of sucrose and the level of liquid in the reactor is not changed.

Key words: saturation reactor, bubble, isothermal, mixing mode, simulation, candied fruit.

\section{Introduction}

The production of candied fruits is a priority development area of the food industry. The basic process in candied fruits production is diffusion of sugar syrup into vegetable raw material. ChemCad's universal simulator allows you to simulate the process of saturation of pumpkin fruit with sugar. The simulation results allow the implementation of a technological process with minimal energy consumption and maximum preservation of nutrients in the finished product, in which the only preservative is sugar.

\section{Methods}

The object of the research was particles of identical sizes of cubic shape (10 mm wide) from the pumpkin fruits of the "Stofunvotka Vassma" kind grown in the western regions of Ukraine. Pumpkin particles were saturated with sugar in syrup with sugar initial concentration of 70 wt. $\%$ using the installation.

With the help of the universal simulation program ChemCad, an isothermal saturation reactor for sugar pumpkin particles was modeled, which operates under the constant concentration of sucrose in syrup and simultaneously increases the concentration of sucrose in candied fruits (Fig.1)

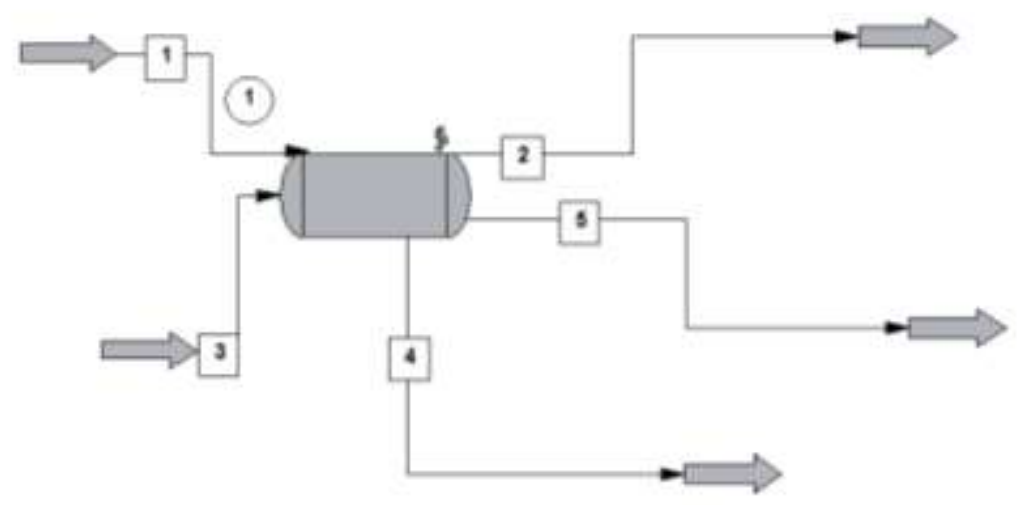

Fig.1. Model Dynamic vessel ChemCad for steady state

1 - feed stream (syrup); 2 - product stream (vapor); 3 - feed stream (pumpkin cubes of 10x10x10 $\mathrm{mm}$ size); 4 - product stream (syrup); 5 - product stream (candied fruit)

Such a process was modeled by stationary with intense mixing, operating in isothermal mode and in which amount of evaporated water compensates for the amount of water extracted from candied fruit. 


\section{Results and discussion}

For simulation, it was necessary to pre-analyze the mathematical description of the conditions for the implementation of the isothermal regime, to develop a mathematical support for the design of the reactor.

For simulation, it was necessary to pre-analyze the mathematical description of the conditions for the implementation of the isothermal regime, to develop a mathematical support for the design of the reactor to include:

- determination of the constant concentration of sugar in vaporized syrup at the end of the process, the flow of solution and vapor;

- duration of sucrose saturation under stationary conditions;

- definition of reactor design characteristics, diameter, height and height of the liquid.

Numerical simulation values, graphical (Fig.2, 3) and computational relationships are obtained, the result is analyzed.

\section{$\mathrm{C}, \mathrm{kg} / \mathrm{kg}$}

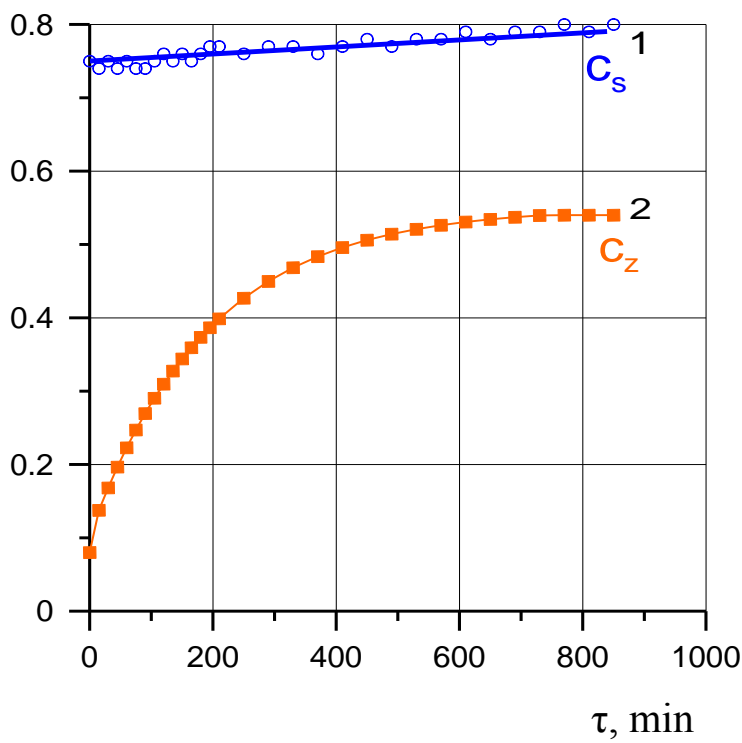

Fig. 2. Dependence of changes in sucrose concentration in syrup (curve 1) and candied fruits (curve 2) in time
$\mathrm{L}, \mathrm{m}$

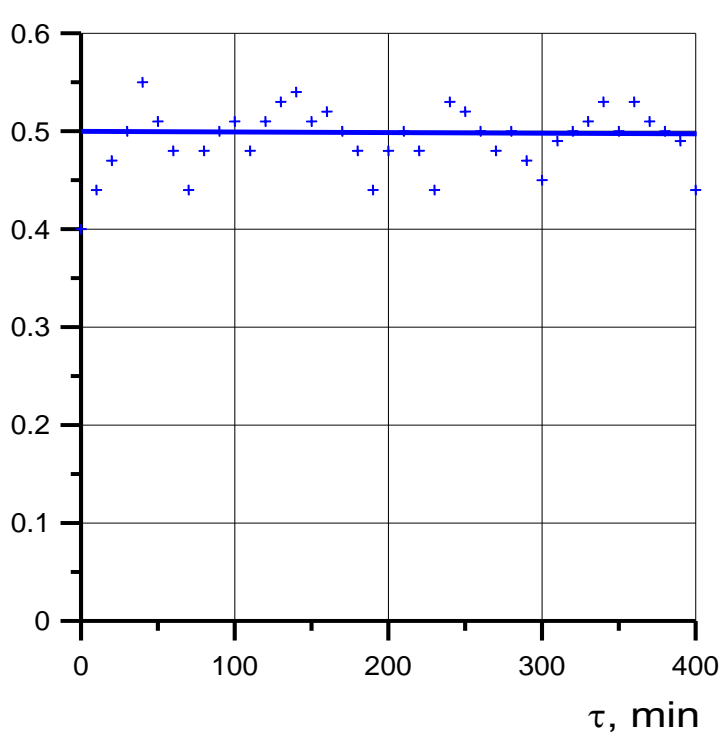

Fig. 3. Dynamics of change in fluid level in time

It is evident from Fig. 2, 3 that concentration of sucrose and the level of liquid in the reactor is not changed.

\section{Conclusion}

It is proved that the process of saturation of succulents with sugar in the steady state is advisable, in terms of preservation of organoleptic properties, optimum saturation of candied fruit, which will retain its properties and molds for a long time.

\section{References}

[1] Iryna Huzova, Volodymyr Atamanyuk. Modelyuvannya izotermichnoho reaktora dlya nasychennya sakharozoyu tsukativ z harbuzy // Naukovi pratsi. - 2018. - T. 82, vyp. 1. - - S. 54-61. 